\title{
Durability and Activity Tunable Pt/Graphene Catalyst for Oxygen Reduction Reactions
}

Piao Zhang, Wenmao Tu*, Rui Wang, Shichang Cai, Jing Wu, Qiong Yan, Hongfei Pan, Haining Zhang, Haolin Tang ${ }^{*}$

State Key Laboratory of Advanced Technology for Materials Synthesis and Processing, Wuhan University of Technology, Wuhan 430070, P. R. China.

*E-mail: tuwm@whut.edu.cn, thln@whut.edu.cn

doi: $10.20964 / 2016.12 .89$

Received: 6 September 2016 / Accepted: 24 October 2016 / Published: 10 November 2016

We report durability and activity tunable Pt/graphene with micropores controllable graphene as the supports for oxygen reduction reactions. The graphene supports are prepared by thermal reduction of few-layered graphite oxide in hydrogen atmosphere. Oxygen atoms emission and carbon atoms rearrangement occur during the thermal reduction at variable temperature, thus form tunable micropores and graphitization degree in the graphene supports. Symmetrical dispersion of $\mathrm{Pt}$ nanoparticles with an medial diameter of $2.3 \mathrm{~nm}$ loaded on stable graphene supports contribute to a supernal electrochemical surface area, enhanced electrochemical catalytic activity and durability toward oxygen reduction reactions compared to mercantile $\mathrm{Pt} / \mathrm{C}$ catalyst. The results demonstrate that durability and activity tunable Pt/graphene is a promising electrocatalyst for oxygen reduction in fuel cells.

Keywords: Durability; Activity tunable; Oxygen reduction reaction; Micropores; Graphene supports.

\section{$\underline{\text { FULL TEXT }}$}

(C) 2016 The Authors. Published by ESG (www.electrochemsci.org). This article is an open access article distributed under the terms and conditions of the Creative Commons Attribution license (http://creativecommons.org/licenses/by/4.0/). 